\title{
REDE DE PROTEÇÃO E POLÍTICAS PÚBLICAS PARA CRIANÇAS E ADOLESCENTES EM SITUAÇÃO DE RISCO NO MARAJÓ (PA)
}

\author{
Ana Elizabeth Neirão Reymão* \\ Arnaldo José Pedrosa Gomes**
}

\begin{abstract}
RESUMO: O objetivo do artigo é discutir a importância do fortalecimento da rede atendimento da criança e do adolescente e as políticas públicas. O estudo é de abordagem qualitativa, tendo como procedimento um estudo de caso sobre o município de Chaves, no Marajó (Pará), além da pesquisa bibliográfica e documental. Discutem-se os direitos resguardados pela Constituição brasileira e pelo Estatuto da Criança e Adolescente, à luz da teoria de Amartya Sen. Como resultado, mostra-se a fragilidade da rede de atendimento para as políticas públicas voltadas à criança e ao adolescente em situação de risco no município em análise.
\end{abstract}

Palavras-chave: Políticas Públicas; Estatuto da Criança e Adolescente; Amartya Sen; Marajó; Direito Fundamental.

\section{NETWORK OF PROTECTION AND PUBLIC POLICIES FOR CHILDREN AND ADOLESCENTS AT RISK IN MARAJÓ (PA)}

\begin{abstract}
The paper discusses the importance of strengthening the child and adolescent care network and public policies. The study has a qualitative approach and is a case study about Chaves, in Marajó (Pará), and uses bibliographical and documentary research. The rights protected by the Brazilian Constitution and by the Statute of the Child and Adolescent are discussed, in the light of Amartya Sen's theory. As a result, the fragility of the care network for public policies directed at children and adolescents in situations of in the municipality under analysis.
\end{abstract}

Keywords: Public Policies; Statute of the Child And Adolescent; Amartya Sen; Marajó; Fundamental Right.

\footnotetext{
* Economista, professora do Programa de Pós-Graduação em Direito, Políticas Públicas e Desenvolvimento do Centro Universitário do Pará (CESUPA) e da Faculdade de Economia da Universidade Federal do Pará (UFPA). Grupo de pesquisas CNPq Emprego, Subemprego e Políticas Públicas na Amazônia (PPGD-CESUPA). E-mail: bethrey@uol.com.br

** Juiz de Direito no Estado do Pará, mestrando do Programa de Pós-Graduação em Direito, Políticas Públicas e Desenvolvimento do Centro Universitário do Estado do Pará (CESUPA). E-mail: arnaldo.pedrosa@bol.com.br
} 


\section{INTRODUÇÃO}

O presente artigo discute a importância de se fortalecer a rede atendimento da criança e do adolescente e as políticas públicas, a partir da análise do caso do município de Chaves, localizado no arquipélago do Marajó, Estado do Pará.

O estado é um dos que se destacam negativamente quanto à violação dos direitos de crianças e adolescentes, tendo o Marajó ficado nacionalmente conhecido pela repercussão de casos emblemáticos denunciados nacionalmente por lideranças populares e religiosas sobre violência sexual (CORSINI, 2013). Há denúncias, também, de trabalho infantil na produção do açaí, sendo as crianças usadas como mão de obra para a coleta do fruto no alto das árvores (FUNDACENTRO; INSTITUTO PEABIRU, 2016).

Chaves é um município localizado na foz do rio Amazonas, cuja população é estimada em 22566 mil habitantes, tendo mais de 13 mil km² de extensão territorial, segundo dados do Instituto Brasileiro de Geografia e Estatística (IBGE). Faz parte do arquipélago do Marajó, um local com uma grande diversidade em seus ecossistemas, rico em belezas naturais. Em contraste, dos 20 municípios com menor Índice de Desenvolvimento Humano (IDH), em 2010, nove são da ilha do Marajó, Melgaço (IDH 0,41), Chaves $(0,45)$ e Bagre $(0,47)$, conforme dados de 2010. Assim, é uma região precária em políticas públicas, nela existindo uma grande incidência de violação aos direitos e garantias da criança e do adolescente.

Os casos mencionados ilustram a importância de se debruçar sobre o tema desenvolvimento das crianças e adolescentes, que são acometidas pela insegurança na aplicação dos direitos e garantias na região. Também são vítimas do abandono das instituições que deveriam fomentar políticas públicas para seu desenvolvimento.

Os direitos da criança e adolescente encontram-se resguardados por tratados internacionais, pela Constituição da República do Brasil e pelo Estatuto da Criança e Adolescente, garantindo a proteção integral e condições dignas humanas, para que possam ter um crescimento e desenvolvimento saudável.

São direitos fundamentais e, como tais, não suprimíveis do ordenamento jurídico e parte daquilo que Amartya Sen (1999) denominou liberdades instrumentais das pessoas. São direitos que aumentam as capacidade das pessoas, pois as liberdades são essencias para o desenvolvimento, auxiliando a tirá-las da pobreza absoluta, cabendo às políticas públicas viabilizarem instrumentos e capacidades para o exercício de sua autonomia e liberdade. 
Nessa perspectiva, o problema de pesquisa desse artigo é: como está constituída a rede de atendimento da criança e adolescente em situação de risco no município em análise?

O estudo é de abordagem qualitativa e, quanto aos procedimentos, a pesquisa é um estudo de caso sobre a cidade de Chaves (PA), mas também baseada em fontes bibliográficas e documentais, como dados do sistema Libra do Tribunal de Justiça do Pará, bem como relatórios do Centro de Referência de Assistência Social (CRAS) de Chaves. Considerando os objetivos propostos, trata-se de uma pesquisa exploratória e descritiva, para a descrição de fatos e fenômenos associados às políticas públicas sobre a criança e o adolescente no município escolhido.

O texto está estruturado em cinco partes, incluindo essa introdução e as considerações finais. A seção dois trata da criança e do adolescente à luz do ordenamento jurídico e do pensamento de Amartya Sen. Políticas públicas e os Conselhos Municipais de Direitos da Criança e do Adolescente e Tutelares são temas abordados na seção três. A seção quatro mostra a fragilidade da rede de atendimento da criança e adolescente em situação de risco no município de Chaves.

\section{A CRIANÇA E O ADOLESCENTE À LUZ DO ORDENAMENTO JURÍDICO E DO PENSAMENTO DE AMARTYA SEN}

\subsection{Os princípios que norteam o direito da criança e do adolescente}

As primeiras Cartas Magnas da República do Brasil falavam da proteção dos direitos civis e políticos dos cidadãos, mas nada era mencionado a respeito da dignidade humana nem dos direitos das meninas e meninos. Somente com a promulgação da Constituição Federal de 1988 (CF/88) é que o Estado começou a se preocupar mais com a dignidade da pessoa humana.

$\mathrm{O}$ documento também inova quanto à criança e ao adolescente, resguardando seus direitos como claúsula pétrea, não sendo possível qualquer alteração que possa diminui-los, implicando em prejuízos para os mesmos.

Destacando a importância de estarem presentes na CF/88, Paganini e Del Moro (2011, p. 4) afirmam: "Sendo os direitos fundamentais algo presente na Constituição da República Federativa do Brasil, nada mais sensato que estes sejam protegidos de qualquer possível abalo jurídico, possibilitando o reconhecimento da condição de cidadão". 
O direito da criança e do adolescente é baseado em alguns princípios tais como: teoria da proteção integral, da prioridade absoluta, descentralização, desjudicialização e o da participação popular e politização.

$\mathrm{O}$ art. $227 \mathrm{da} \mathrm{CF} / 88$, em seu $\S 3^{\circ}$, vem trazendo princípio da proteção integral à criança e ao adolescente, assim dispondo:

\begin{abstract}
A criança e o adolescente gozam de todos os direitos fundamentais inerentes à pessoa humana, sem prejuízo da proteção integral de que trata esta Lei, assegurandose-lhes, por lei ou por outros meios, todas as oportunidades e facilidades, a fim de lhes facultar o desenvolvimento físico, mental, moral, espiritual e social, em condições de liberdade e de dignidade.
\end{abstract}

Com fundamento no princípio supracitado, faz com que ocorra o reconhecimento dos direitos fundamentais a todos os meninos e meninas, declarando estes como sujeitos de seus próprios direitos.

Conquanto, há o princípio da prioridade absoluta previsto no artigo $4^{\circ}$, parágrafo único do Estatuto da Criança e do Adolescente:

a) primazia de receber proteção e socorro em quaisquer circunstâncias; b) precedência de atendimento nos serviços públicos ou de relevância pública; c) preferência na formulação e na execução das políticas sociais públicas; d) destinação privilegiada de recursos públicos nas áreas relacionadas com a proteção à infância e à juventude.

O princípio da descentralização, por sua vez, afirma que as políticas públicas devem ser exercidas no local em que os meninos e meninas têm sua residência, para que seja atingido o objetivo de suas decisões com a realidade de cada criança e adolescente. Essa descentralização político-administrativa visa dar eficácia às ações governamentais e não-governamentais em termos de políticas públicas, destacam Paganini e Del Moro (2011), pois divide a competência para atuação entre os entes da federação e dos demais seguimentos da sociedade civil organizada, ampliando as possibilidades de legitimar os programas e ações sociais.

Pelo princípio da desjudicialização, entende-se como atribuição de órgãos estatais, reunidos para a promoção de políticas públicas, ser importante evitar a judicilização de situações fáticas, em matérias reservadas ao Estatuto da Criança e Adolescente. Com base nas atribuições desses órgãos, espera-se não apenas que implementam tais políticas, mas que evitem o conflito do direito da criança e do adolescente no poder judiciário, devendo sua implementação ser efetivada pelo poder executivo.

Quanto ao princípio basilar da participação popular, frisa-se que é de elevada importância a promoção de políticas públicas por parte do Estado, pois proporciona a 
participação especiais de órgãos como: Conselhos Tutelares, Conselho de Direitos, Fórum de Direitos bem como nas Conferências de Direitos da Criança e do Adolescente, cabendo-lhes a fiscalização e promoção de políticas públicas.

Para a efetivação das políticas públicas, destaca-se o princípio da politização, cujo objetivo é buscar e auxiliar a prática na efetividade das políticas públicas, pois não deverá seguir as políticas assistencialisticas, que são dirigidas e conduzidas para determinados grupos selecionados de forma aleatória e sem qualquer critérios quantitativos e específicos, servindo este princípio para efetivar políticas que garantam os direitos relacionados à criança e adolescente.

Por fim, destaca-se a teoria de proteção integral, segundo a qual deve-se estender a todas as crianças e adolescentes o reconhecimento dos direitos fundamentais inerentes à pessoa humana e, ainda, dos direitos especiais decorrentes da condição peculiar de pessoa em desenvolvimento. Com ela, rompeu-se com antigo código de menores de 1927, embora ele ainda se encontre tão presente na consciência dos aplicadores do direito e da sociedade de um modo geral (PAGANINI; DEL MORO, 2011).

\subsection{Sobre os direitos da criança e adolescentes}

A criança e o adolescente têm o direito ao reconhecimento como pessoa sujeito de direito, pois quando a sociedade nos trata sistematicamente como inferiores, internalizamos uma imagem negativa de nós mesmos e passamos a moldar as nossas escolhas e ações a partir dela, tendemos a não desenvolver a auto-estima.

A palavra "reconhecimento" não denota a mera identificação do outro. O reconhecimento é associado à valorização da pessoa reconhecida, em atitude que lhe expressam o devido respeito, por isso que o ordenamento jurídico tem que reconhecer a criança como sujeito de direito e obrigações, resguardando-lhe a dignidade da pessoa humana.

A negação de reconhecimento equivale ao desrespeito. Trata-se de comportamento que não apenas insulta as pessoas ou lhes inflinge dano, como também degrada a sua alto imagem. Nessa perspectiva, Sarmento (2016) desdobrou o reconhecimento em três esferas: amor, direito e solidariedade. E aludiu, por outro lado, as três formas básicas de reconhecimento, que correspondem, respectivamente à: violação, privação de direitos e degradação.

Desta forma, é indubtavelmente necessário que o ordenamento jurídico, ampare e dê total proteção à criança e o adolescente, regulando os seus direitos e suas garantias, superando 
a noção de que o adulto é superior a tudo, o que possibilitava que as transgressões contra a criança e o adolescente não fossem penalizadas e apuradas, retirando assim o seu pleno desenvolvimento emocional e físico.

De acordo com o artigo $2^{\circ}$ do Estatuto da Criança e do Adolescente de 1990, considerase criança a pessoa até doze anos de idade incompletos. Adolescente, por sua vez, é a que possui entre doze e dezoito anos de idade.

É nessa fase em que as crianças descobrem suas fantasias, brincadeiras, aprendizados e os adolescentes e suas potencialidades, desfrutando assim sua condição de cidadão de modo que seus direitos são assegurados. Por esse motivo, a criança e o adolescente passaram a serem reconhecidas como sujeitos de direitos, sendo detentores de sua própria história e jamais inferiorizados perante os adultos.

O art. 1 da Declaração Universal dos Direitos Humanos (1948) dispõe que: “Todos os seres humanos nascem livres, sendo iguais em dignidades e direitos, onde eles são dotados de razão e consciência e devem interagir com relação aos outros com espírito de fraternidade."

A Convenção dos Direitos da Criança e do Adolescente em 1989 em seu art. $1^{\circ}$, entende por criança, todo ser humano, com menos de 18 anos de idade, salvo, se nos termos da lei que lhe for aplicável, atingir a maioridade mais cedo.

Assim quando falamos em dignidade é possível lembrar de um dos princípios mais importantes da CF/88, que trata da Dignidade da Pessoa Humana, o qual protege e reconhece a criança e o adolescente que sofre qualquer tipo de violência aos seus direitos e garantias.

Rompe-se, com base no supracitado, o modelo do Código de Menor, no qual a criança e o adolescente eram considerados objetos, utilizados enquanto durassem suas curtas vidas.

Desta forma, a partir do momento que se é estabelecido quem pode ser reconhecido como criança e adolescente, passam a existir uma grande gama de direitos e garantias. Uma vez que os direitos e garantias que os adultos possuem são resguardados, de igual modo para os meninos e meninas, fazendo assim com que eles também sejam possuidores de direitos e garantias destinados aos adultos.

Com isso é de fundamental importância estabelecer um marco de idade para a criança e o adolescente, como fez o Estatuto da Criança e do Adolescente. Porém, a legislação por si só não é capaz de resguardar esses direitos e muitas práticas cruéis continuam sendo realizadas.

Diante disto, é oportuno que haja o efetivo envolvimento de toda a comunidade, assim como também da rede de proteção de atendimento da criança e adolescente, na fiscalização dos 
direitos de meninas e meninos, para que não ocorram violações aos direitos e garantias a eles dirigidos.

A sociedade tem um papel fundamental nessa proteção, sendo sua participação ativa na vida política do Estado de suma importância, podendo influenciar na elaboração e implementação de políticas públicas para a proteção destes direitos, mas muitas das vezes se cala diante das transgressões dos direitos e garantias reguardos na Constituição Federal, apresentados na seção a seguir.

2.3 O direito fundamental da criança e adolescente e o pensamento de Amartya Sen

A Carta Magna da República Federativa do Brasil, CF/88, relacionou uma gama de direitos fundamentais da criança e adolescente, os quais não tinham sidos instituídos pelas Constituições anteriores. Dispõe seu artigo 227:

É dever da família, da sociedade e do Estado assegurar à criança, ao adolescente e jovem, com absoluta prioridade, o direito à vida, à saúde, à alimentação, à educação, ao lazer, à profissionalização, à cultura, à dignidade, ao respeito, à liberdade e à convivência familiar e comunitária, além de colocá-los a salvo de toda forma de negligência, discriminação, exploração, violência, crueldade e opressão (BRASIL, 1988, não paginada).

Os direitos fundamentais acima definidos, assim denominados por estarem previstos na Constituição Federal do Brasil, e interpretados pela doutrina como claúsulas petréas, são considerados não suprimíveis do ordenamento jurídico. E mais, como nos lembra Amartya Sen, são parte das chamadas liberdades instrumentais das pessoas: "As liberdades instrumentais, tais os direitos fundamentais, aumentam diretamente a capacidade das pessoas, mas também suplementam-se mutuamente e podem, além disso reforçar umas as outras” (SEN, 1999, p. 61).

Tais liberdades são essencias para o desenvolvimento, uma vez que esse não é, simplesmente econômico, mas também melhora na expectativa de vida, na educação, na saúde, e em outras dimensões da vida da pessoa, defende Sen (1999). E mais, são os direitos, como os fundamentais, as garantias protetoras, que tiram o indivíduo da pobreza absoluta, viabilizando instrumentos e capacidades para o exercício da autonomia e da liberdade:

O desenvolvimento requer que se removam as principais fontes de liberdade: pobreza e tirania, carência de oportunidades econômicas e destituição social 
sistemática, negligência de servicos públicos (grifo nosso) e intolerância ou interferência excessiva de Estados repressivos (SEN, 1999, p. 16-17).

Mais adiante, o autor destaca a importância da expansão dos serviços de saúde, educação, seguridade social e outros para a qualidade da vida e seu florescimento:

O que o desenvolvimento humano faz? A criação de oportunidade sociais contribue diretamente para a espansão das capacidades humanas e da qualidade de vida (como já exposto). A expansão dos serviços de saúde, educação (negrito nosso), seguridade social (...) contribuem diretamente para a qualidade da vida e seu florescimento. Há evidências até de que mesmo com rendas relativamente baixas, um país que garante um serviço de saúde e eduçação a todos pode obter resultados notáveis da duração e qualidade de vida de toda a população (SEN, 1999, p. 190).

A negligência de serviços públicos de proteção da criança e adolescente, podem impor sérios prejuízos para proteger os direitos e garantias de liberdade destes:

Em outros casos, a privação de liberdade vincula-se extritamente à carência de serviços públicos e assistência social, como por exemplo a ausência de programas epidmológicos, de um sistema bem planejado de assistência médica e educação ou de instituições eficazes para a manutenção da paz e da ordem locais. Em outros casos, a violação da liberdade resulta diretamente de uma negação de liberdades políticas e civis por regimes autoritários e de restrições impostas a liberdade de participação da vida social, política e econômica da comunidade (SEN, 1999, p. 17).

Assim, é a partir desses direitos fundamentais anunciados na $\mathrm{CF} / 88$ que o Estatuto da Criança e do Adolescente trata da implantação de medidas protetivas e de outras ações no sentido de fortalecê-los e superar a cultura que priveligiava o revogado código do menor, concretizando os princípios e diretrizes da teoria da proteção integral, cujo obetivo é resguardar os direitos das crianças e adolescente em determimento às ofensa a direitos e garantias, destacam Paganini e Del Moro (2011).

Com o escopo de garantir o direito fundamental à saúde, a Carta Magna reconheceu, em seu artigo $7^{\circ}$, incisos IV e XXII, como instrumento de melhoria das condições sociais, ratificando no artigo 30 que: "É dever do Estado através dos municípios garantir os serviços necessários ao atendimento integral de toda população” (BRASIL, 1988, não paginada).

De acordo com o artigo 194, da CF/88, a saúde é um dos objetivos da seguridade social, sendo efetivado por meio da criação do Sistema Único de Saúde. A respeito da importância desta instituição, destaca-se mais uma vez a lição de Sen, quando afirma: 
Precisamos, então, de uma estrutura avaliatória apropriada, precisamos também de instituições que atuem para promover nossos objetivos e comprometimentos valorativos e, ademais, de normas de comportamento e de um raciocínio sobre o comportamento que nos permitam realizar o que tentamos realizar (SEN, 1999, p. 118) (grifo nosso).

Assim, sendo a liberdade a finalidade do desenvolvimento, na ótica de Sen (1999), destaca o autor que a presença do Estado, por meio de políticas públicas, é fundamental para que o indivíduo seja livre, agindo aquele como garantidor e promovedor de direitos sociais que emancipam o indivíduo.

O exercício da liberdade, desse modo, perpassa pela ampliação das capacidades, pelo amparo do Estado, uma vez que não existe liberdade sem a responsabilidade anterior desse ente, garantindo direitos e oportunidades.

Nessa perspectiva, o Estatuto da Criança e do Adolescente destacam uma série de direitos, como o à saúde e à educação, dentre outros. Em seu artigo $7^{\circ}$, ressalta que a criança e o adolescente têm o direito à saúde, sendo o poder público o responsável para concretizar as política sociais, eleborando-as, de forma que permitam desenvolvimento sadio de meninos e meninas. Nesse diapasão, apresenta o Sistema Único de Saúde como instituição responsável pelo atendimento destes, devendo lhes ser garantido o acesso universal e igualitário às ações e serviços para promoção, proteção e recuperação, nos termos da CF/88.

O Sistema Único de Saúde é uma estruturra criada pela Constituição Federal de 1988, instituida e apropriada para promover os objetivos que tratam da saúde pública do cidadão brasileiro. Uma de suas finalidades é o atendimento a crianças e adolescentes quando têm seus direitos violados.

Outro ponto importante trazido pelo mesmo Estatuto da Criança e do Adolescente é em relação à gestante, reconhecendo, em seu artigo $8^{\circ}$, a proteção à criança desde a concepção, tendo a gestante a garantia de ser amparada por meio do Sistema Único de Saúde para obter efetivo atendimento.

No artigo 13, destaca que os profissionais da rede de atenção à saúde têm a obrigação de comunicar ao Conselho Tutelar os casos de suspeita ou confirmação de maus-tratos, e providenciar o encaminhamento para serviços especializados. Assim, observa-se aqui o princípio da tríplice responsabilidade compartilhada, segundo o qual o Estado, a família e a sociedade têm a obrigação de garantir o atendimento a criança e adolescente de modo efetivo. 
$\mathrm{O}$ artigo 15 do mesmo Estatuto dispõe que a criança e adolescente tem direito à liberdade, o respeito e dignidade. Já o artigo 16 trata de estabelecer diretrizes que compreendem tal liberdade, cujo finalidade é assegurar sua inviolabilidade destes direitos. $\mathrm{O}$ art. 17 destaca a importância de preservar a garantia da integridade física, psicológica e moral da criança e do adolescente, da imagem, identidade, autonomia, valores, ideias, crenças, espaços e objetos pessoais.

O artigo 19, por sua vez, dispõe que a convivência familiar e comunitária é um direito reservado a toda criança e adolescente e sua criação e educação devem ser no seio familiar. Caso a criança não possua parentes sanguíneos, faz-se necessário serem criadas em família substituta.

Outro ponto importante é quanto à necessidade de que o poder público resguarde para a criança e adolescente um aprendizado de boa qualidade, de acordo com a necessidade social de cada um, de modo que os mesmos criem um real interesse, estejam motivados o suficiente para a descoberta de novos saberes e lhe seja viabilizado um pleno desenvolvimento intelectual e social. Conquanto, antes da Carta Magna de 1988, não existia a preocupação em criar instrumentos necessários para garantir o direito à educação.

O referido Estatuto ressalta, ainda, que as crianças e adolescentes que sofrem algum tipo de violação de seus direitos devem ser afastados de sua família, devendo a rede de atendimento e o poder público, por meio de seus serviços, atender adequadamente e socorrer os mesmos dos maus tratos e não negligenciar os serviços de atendimento.

Por fim, cumpre destacar que a criança e o adolescente são sujeitos de direitos e possuidores das garantias fundamentais previstas na Constituição, mas isso não basta para que os mesmos sejam plenamente assegurados. É necessário, uma articulação entre o poder público e a sociedade para que esses direitos e garantias sejam efetivados, por meio de políticas públicas, como discute a seção a seguir.

\section{POLÍTICAS PÚBLICAS E OS CONSELHOS MUNICIPAIS DE DIREITOS DA CRIANÇA E DO ADOLESCENTE E TUTELARES}

O Estado e a sociedade têm papel fundamental para implementação de políticas públicas quanto aos direitos da criança e adolescente, devendo promovê-las e estimular a rede de proteção da criança e adolescente em situação de risco. 
Política pública é, na visão de Dye (1984, p.2), “o que o governo escolhe fazer ou não fazer”. Assim, trata-se não apenas da ação, mas também da inação do governo, pois ambos resultam em importantes impactos para problemas públicos.

Outros autores também definem políticas públicas, como Laswell (1958), que as define como um programa planejado de objetivos, valores e práticas dos governos. Indaga o autor: quem ganha o quê, por quê e que diferença faz? Guy Peters (1986), por sua vez, as conceitua como a soma das atividades dos governos, que agem diretamente ou por meio de delegação, e que influenciam a vida dos cidadãos.

Enfim, embora não haja apenas um conceito para políticas públicas, pode-se observar uma certa complementariedade nas definições aqui apresentadas e que, em todos eles, remetese a ideia de políticas públicas à ação (ou inação) do Estado.

Nessa linha, Duarte (2013) destaca que as instituições governamentais dão às políticas públicas pelo três características essenciais: legitimidade, universalidade e coercitividade. A primeira relaciona-se ao fato de que uma política pública deve derivar da Constituição, de tratados internacionais ratificados pelo Brasil ou por leis infraconstitucionais. A segunda, relativa à universalidade, refere-se ao fato de que ela deve ser extensiva a todos, ao menos todos que fazem parte de um determinado grupo ou setor vulnerável da sociedade a justificar um atendimento prioritário. Por fim, a coercibilidade significa que, se os parâmetros definidos por uma política pública forem violados pelos cidadãos, os mesmos estarão sujeitos a sanções por parte do Estado.

Fábio Comparato, na década de 1980, introduziu o conceito de política públicas como instrumento do Estado Social, para a efetivação dos direitos fundamentais, trazendo o princípio da soliderariedade como vetor para a solução desta tensão entre a liberdade e igualdade, afirmando:

A cidadania, que ganhou uma nova visão constitucional em 1988, passando a ser fundamento do nosso Estado Democrático e Social de Direito, com amplos direitos assegurados na Constituição, precisa ser efetivada em nossa vida social, deixando de ser apenas uma previsão formal do sistema jurídico (COMPARATO, 2008, p.124).

Cidadania e direitos fundamentais passam a constituir um "Núcleo Duro" do chamado Estado democrático e social de direito, trazendo políticas públicas para o centro do debate políitico e jurídico. 
No caso das políticas públicas para a criança e o adolescente, um grande desafio a ser enfrentado, entre tantos, é a estruturação de um "Sistema de Garantias" completo, com prioridade para a criação dos Conselhos Municipais de Direitos da Criança e do Adolescente e Tutelares, sendo a existência daqueles indispensável à elaboração de verdadeiras e legítimas políticas públicas intersetoriais para o atendimento das necessidades específicas da população infanto-juvenil local e à própria capacitação dos autores formadores do sistema.

Tal Conselho é um órgão composto por representantes da sociedade civil e do governo, responsável pelo controle e acompanhamento das políticas públicas da criança e adolecente. Sendo indespensável uma interação entre os atores da rede de atendimento ao público infantojuvenil, para a promoção dos direitos e garantias que as normas e os tratados lhe garante, os Conselhos Municipais dos Direitos da Criança e do Adolescente têm o dever institucional de promover a articulação dos demais integrantes do "sistema de garantias", procurando otimizar a atuação de cada um e coordenar as intervenções conjuntas e/ou interinstitucionais, de modo a atender as mais variadas demandas existentes no município.

Ademais, cabe aos Conselhos Municipais de Direitos da Criança e do Adolescente a tarefa e irrecusável papel de colocar em uma mesma mesa de debates os representantes de todos os órgãos e instituições que atuam direta ou indiretamente com crianças e adolescentes, para que, juntos, pontuem e discutam os maiores problemas que afligem a população infanto-juvenil local, planejando ações e definindo estratégias de atuação interinstitucional para sua efetiva solução.

Assim apresentados, passa-se a analisar a rede de atendimento da criança e adolescente em situação de risco, e as políticas públicas na cidade de Chaves, conforme seção a seguir.

\section{A FRAGILIDADE DA REDE DE ATENDIMENTO DA CRIANÇA E ADOLESCENTE EM SITUAÇÃO DE RISCO NA CIDADE DE CHAVES, NO ARQUIPÉLAGO DO MARAJÓ, ESTADO DO PARÁ}

No Município de Chaves encontra-se instalada uma Comarca do Tribunal de Justiça do Estado do Pará, de vara única, que tem a função de julgar, em primeira instância, processo referente a infância e juventude, garantindo seus direitos como sujeito de direitos.

Encontravam-se tramitando na comarca 607 (seiscentos e sete) processos, conforme sistema Libra do Tribunal de Justiça, acessado em 21 de dezembro de 2017, dos quais 13 (treze) 
são contra a criança e adolescente, 07 (sete) já foram sentenciados e foram aplicadas medidas socieducativa, e 06 (seis) estão na fase de instrução.

O Ministério Público Estadual tem a atribuição de zelar pela efetivo respeito aos direitos e garantias legais asseguradas à criança e adolescente, sendo uma das portas de entrada para a apuração de violação dos direitos da criança e adolescente no Munícipio de Chaves, encontra-se com 01 (um) membro lotado na Comarca.

A Defensoria Pública Estadual presta assistência judiciária gratuita nas ações de competência da justiça da infância e juventude, apesar de instalada no Fórum de Chaves, mas não existe Defensor Público lotado na Comarca.

O Advogado da Assistência Social da Prefeitura, tem sido nomeado como Defensor Dativo, para atuar nos processos em que o adolescente e a criança estão desassistidos por advogado e pela defensoria pública.

A Delegacia de Polícia, responsável pela apuração de ato infracional contra a criança e adolescente, no Município de Chaves, possuia 20 (vinte) inquéritos por ato infracional, em fins de 2017. Frise-se que na Comarca não tem Delegacia especializada para apuração de ato infracional, bem como não existe Delegado titular da Delegacia local. Quem responde pela Delegacia de Chaves é o Delegado de Afuá, município vizinho.

O Conselho Tutelar é um órgão permanente e autônomo, não jurisdicional, encarregado pela sociedade de zelar pelo cumprimento dos direitos da criança e do adolescente, definidos no artigo 131 no Estatuto da Criança e Adolescente, já mencionados nesse artigo. Encontra-se instalado na cidade Chaves desde $2004^{1}$.

O Conselho Municipal dos Direitos da Criança e do Adolescente (CMDCA), já referido na seção anterior, é responsável pelo controle e acompanhamento das políticas públicas da criança e adolecente na cidade de Chaves. Porém, embora implementado, não se encontra formalmente regularizado pendente de incrição na Receita Federal, pois a ata de formação e eleição do Conselho, não foi devidamente registrada, os seus componentes não conhecem devidamente as suas atribuições, necessitando assim de uma capacitação para desempenhar as suas funções.

O Centro de Referência de Assistência Social (CRAS) oferece serviços de proteção e atendimento integral à família e serviço de convivência e fortalecimento de vínculos à criança.

\footnotetext{
${ }^{1}$ Mesmo os cargos prenchidos com todos os titulares desempenhando a sua função, a pesquisa, em visita ao município, verificou que seria necessário uma maior capacitação para o desempenho da função de conselheiro tutelar.
} 
É uma unidade de proteção social básica do SUAS, que tem por objetivo prevenir a ocorrência de situações de vulnerabilidades e riscos sociais nos municípios, por meio do desenvolvimento de potencialidade e aquisições, do fortalecimento de vínculos familiares e comunitários, e da ampliação do acesso aos direitos de cidadania.

Embora também instalado no município de Chaves, possui muitas dificuldades no atendimento da criança e adolescentes e para sua família, contando com poucos programas para inserção dos mesmos.

Como mostra o relatório do Centro de Referência de Assistência Social do Município de Chaves, no ano de 2017 o CRAS realizou os seguintes atendimentos:

- Família em acompanhamento, Serviço de proteção e atendimento integral a família (PAIF): 107;

- Acompanhamento de indivíduos pelo PAIF: 252;

- Família de beneficiário de benefício de prestação continuada (BPC), na escola em acompanhamento pelo PAIF: 28;

- Número de beneficiários do BPC na escola: 05;

- Visitas domiciliares: 176;

O Centro de Referência Especializado de Assistência Social (CREAS) é uma unidade pública estatal responsável pela organização e oferta de serviços de proteção social especial do Sistema Único de Assistência Social (SUAS). Presta apoio, orientação e acompanhamento a famílias com um ou mais de seus membros em situação de ameaça ou violação de direitos.

Embora também já esteja instalado na Comarca de Chaves, possuindo alguns programas de atendimento a criança e adolescente, os mesmos têm baixa capilaridade para promoção das políticas públicas de incentivos e desenvolvimento da criança e adolescente no Munícipio.

Tome-se como exemplo o Programa de Atendimento especializado a família e indivíduo (PAEFI), que atendeu um número muito pequeno de famílias em 2017: apenas 600, como mostram os dados de seu relatório.

Outra ação mencionada no documento é a realização de eventos pelo serviço de abordagem social na Município de Chaves, tendo ocorrido apenas 2 (dois) eventos em maio, 2 em junho, 8 em julho e 2 em outubro de 2017. Os temas tratados foram: Dia mundial do combate 
ao abuso e a exploração sexual à criança e adolescente, dia mundial de combate à pessoa com deficiência, violência contra a mulher, dia internacional de combate às drogas.

Como se observa, a atuação do CREAS e do CRAS no Município de Chaves é bastante deficiente, pois conta com poucos profissionais para o atendimento da população local. Estas instituições estão localizadas na área urbana, mas boa parte da população do munícipio encontra-se no interior. Essa situação dificulta o deslocamento tanto da população, que necessita do atendimento, bem como profissionias que o realizam, uma vez que este deslocamento é realizado por meio de pequenas embarcações, sendo os locais de difícil acesso até as comunidades ribeirinhas. Asssim, como em boa parte dos casos as crianças, adolecentes e responsáveis não dispõem de transporte, sequer há registro da violação ou do atendimento da mesma.

É uma triste realidade, ainda que o estado do Pará tenha tido, para o período de 2014 a 2016, um plano de enfrentamento ao abuso e exploração sexual da criança e adolescente, cuja finalidade era combater a impunidade, restaurar direitos e dignidade de vítimas de violência sexual, promover a inclusão social, produzindo assim pontos positivos para o desenvolvimento das crianças e adolescentes paraenses.

Um novo plano de enfrentamento ainda está em fase de teste e alguns órgãos que estão em seu processo de elaboração e reformulação tentam transformá-lo em um plano decenal, este plano é um documento que tem o objetivo de desenvolver as políticas públicas para enfrentar e prevenir esses crimes no Estado do Pará. No entanto, o Município de Chaves não utiliza esse plano como política pública para o enfrentamento do abuso e exploração sexual da criança e adolescente, ficando sua ação limitada à realização de eventos de conscientazação à população no dia 18 de maio de cada ano.

Desde 2017 o representante Ministério Público Estadual no Município de Chaves, juntamente com o membro do Tribunal de Justiça do Estado e a rede de atendimento, têm demonstrado interesse para implementarem um plano municipal com políticas públicas para o enfrentamento de abusos e garantias de direitos da criança e adolescente, fato que, até a conclusão desse atigo, ainda não havia se concretizado, mas sinaliza positivamente para reverter esse grave problema que vivencia o município. 


\section{CONSIDERAÇÕES FINAIS}

O texto mostrou a fragilidade da rede de atendimento da criança e adolescente em situação de risco em Chaves, estado do Pará. Localizado no Marajó, o município tem registrado altos índices de violência sexual contra crianças e adolescentes, bem como de trabalho infantil, questões públicas que requerem da sociedade, ou seja, governos e sociedade civil, uma resposta.

No entanto, os indicadores socioeconômicos do município são baixos e observa-se a ausência de políticas públicas efetivas, mostrando que a região é historicamente abandonada pela falta ou baixa capilaridade das mesmas, de serviços infraestruturais e de equipamentos coletivos de promoção e proteção social voltados para o desenvolvimento socioterritorial.

Apesar de existir, a rede de atendimento em análise revelou-se pequena e desarticulada, necessitando ser restruturada e reaparelhada, com capacitação de seus profissionais e agentes, delimitando as funções e atribuições de suas atividades, para que as crianças e adolescentes possam utilizar de forma adequada e conseguir manter os direitos básicos para o seu pleno desenvolvimento.

A falta de atendimento e garantia de direitos da criança e adolescente tem produzido problemas de ordens diversas, como fome, miséria, abuso e exploração sexual de crianças e adolescentes.

Diante disto, é importante o envolvimento da comunidade local e da rede de proteção e atendimento da criança e adolescente, no combate e fiscalização dos direitos de meninas e meninos para que se possam evitar tais violações.

Por vezes, é mais conveniente que as comunidades e os poderes silenciem diante dos abusos de direitos e garantias, mesmos aqueles previstos na Constituição. No entanto, esquecem dos prejuízos que acarretaram para esses meninos e meninas e para a população local.

A criança e o adolescente são sujeitos de direitos e possuidores das garantias fundamentais previstas na Constituição, mas assegurá-los depende de uma articulação entre o poder público e a sociedade. As políticas públicas, tendo como base o ensinamento de Thomas Dye (1984), envolvem o que se escolhe fazer ou não fazer. Trata-se não apenas da ação, mas também da inação, pois ambos resultam em importantes impactos para problemas públicos. $\mathrm{O}$ não agir, a omissão, conciente ou inconsciente da sociedade em relação aos abusos aos direitos e garantias da criança e do adolescente resultam em um grave obstáculo para o desenvolvimento. 
Somente por meio da participação ativa da comunidade junto ao poder público é que se atingirá com maior efetividade os serviços prestados ao cidadão. Assim, é primordial frisar que tal participação não constitui um ato de bondade do Estado para com estes, todavia um dever de prestar ao cidadão esse direito, devendo ser exigido por toda a sociedade, defende Sen (1999). Nesse sentido, é importante que haja uma real mobilização dos sujeitos sociais para a promoção e efetivação de políticas públicas relacionadas à proteção dos direitos da criança e adolescente no município.

\section{REFERÊNCIAS}

BRASIL. Constituição Federativa de 1988. Disponível em: http://www.planalto.gov.br/ccivil_03/constituição/constituição,html. Acesso em: 11 dez. 2017.

Lei 8.069/90. Estatuto da Criança e do Adolescente. 2009. Disponível em:http://www.planalto.gov.br/ccivil_03/leis/18069,htm. Acesso em: 11 dez. 2017.

COMPARATO, Fábio Konder. Ensaio sobre o juízo de constitucionalidade das políticas públicas. In MELLO, Celso Antônio Bandeira de (org.). Direito Administrativo e Constitucional. Estudo sem Homenagem a Geraldo Ataliba, vol. 2, Malheiros Editores, 1997.

CORSINI, Flávio. Política pública de enfrentamento à violência sexual contra crianças e adolescentes: um olhar amazônico, o caso do Pará. Revista Científica do Núcleo de Pesquisas Eleitorais e Políticas da Amazônia - NUPEPA/UFRR, Volume 01, Número 02, 2013, p. 178192.

DUARTE, Clarisse Seixas. O ciclo das políticas públicas. In: SMANIO, Gianpaolo Poggio. BERTOLIN, Patrícia Tuma Martins. O Direito e as Políticas Públicas no Brasil. São Paulo: Atlas, 2013, p. 16-43.

DYE, Thomas R. Understanding Public Policy. Englewood Cliffs, N.J.: Prentice-Hall, 1984,

FUNDACENTRO; INSTITUTO PEABIRU. O peconheiro. Relatório final para o Programa Trabalho Seguro. Belém (PA), 2016. Disponível em: $<$ https://institutopeabiru.files.wordpress.com/2016/11/o-peconheiro-diagnostico-acai-peabirufundacentro.pdf $>$. Acesso em: 15 mar. 2018.

INSTITUTO BRASILEIRO DE GEOGRAFIA ESTATÍSTICA (IBGE). Cidades. Disponível em : <https://cidades.ibge.gov.br/painel/historico.php?codmun=150250>. Acesso em: 15 nov. 2017.

LASWELL, H.D. Politics: Who Gets What, When, How. Cleveland, Meridian Books, 1958. 
LIMA, Fernanda da Silva. A implementação das ações afirmativas para a concretização dos direitos de crianças e adolescentes negros no Brasil. 2007. Monografia (Graduação em Direito) - Universidade do Extremo Sul Catarinense, Criciúma.

PAGANINI, Juliana; DEL MORO, Rosângela. A utilização dos princípios do direito da criança e do adolescente como mecanismos de efetivação dos direitos fundamentais. Amicus Curiae, v. 6, p. 1-13, 2011.

PETERS, B. Guy. American Public Policy. Chatham, N.J.: Chatham House, 1986.

PIERSON, Lia Cristina Campo. Políticas públicas, opinião pública e agenda setting. In: SMANIO, Gianpaolo. BERTOLIN, Patrícia Tuma Martins. O direito e às políticas públicas no Brasil, São Paulo: Atlas, 2013, p. 156- 168.

SARMENTO, Daniel, Dignidade da pessoa humana, conteúdo, trajetória e metodologia. Belo Horizonte: Ed. Forúm, 2016.

SEN, Amartya. Desenvolvimento como liberdade. São Paulo: Ed. Companhia de Bolso, 1999. 